\title{
A descoberta do plano de ensino e aprendizagem (PEA) como instrumento reflexivo na docência
}

\author{
The Discovery of Teaching and Learning Plan as a reflexive tool for \\ Faculty members.
}

Rodrigo Humberto Flauzino ${ }^{1}$ (D), Cristiane Martins Peres $^{2}$ (D), Fábio Carmona ${ }^{3}$ (D)

\begin{abstract}
RESUMO:
O processo educativo vivenciado por estudantes e professores deve ser focado na aquisição de conhecimento, habilidades e atitudes relevantes para compreensão dos fenômenos da vida e sua aplicação na prática profissional, exigindo a participação ativa e efetiva dos muitos envolvidos: estudantes, professores, gestores acadêmicos e outros atores importantes. Ainda que essa máxima faça parte dos discursos dos cursos da área da saúde, ressalta-se, neste trabalho, o valor fundamental do planejamento para uma ação educacional de qualidade. A adoção de instrumentos pedagógicos próprios para este fim pode favorecer uma melhor reflexão, desenvolvimento e comunicação do percurso de formação dos estudantes. Na Faculdade de Medicina de Ribeirão Preto, Universidade de São Paulo (FMRP-USP), o instrumento utilizado é conhecido como Plano de Ensino e Aprendizagem, o PEA. Neste relato de experiência, apresenta-se o seu contexto de implementação, as discussões envolvendo a comunidade acadêmica, as ações formativas para torná-lo um recurso vivo e potente para o fazer docente, elementos estes que fortaleceram o ensino nos cursos de graduação da FMRP. Ao longo deste artigo, o leitor conhecerá as partes que compõem o PEA, orientações sobre como elaborá-lo, exemplos produzidos por professores e um conjunto de rubricas e critérios que contribuem para nortear o planejamento no contexto da docência nas profissões da saúde.
\end{abstract}

Palavras-chave: Planejamento Educacional; Educação Superior; Saúde; Docência; Capacitação de Professores.

\begin{abstract}
:
The educational process experienced by students and University professors must be focused on acquiring knowledge, skills and attitudes relevant to understand the phenomena of life and their application in professional practice. This requires the active and effective participation of the many players involved. In the present investigation, the fundamental value of planning for a quality educational action is emphasized. The implementation of specific pedagogical instruments may favor a better reflection, development and communication of the students' training path. In our university campus At the Ribeirão Preto Medical School, University of São Paulo (FMRP-USP), the instrument used is known as the Teaching and Learning Plan, the "PEA". In this experience report, its implementation context is presented, the discussions involving the academic community, the training actions to make it a living and powerful resource for teaching, elements that strengthened the teaching in FMRP undergraduate courses. Throughout this article, the reader will learn about the parts that make up the "PEA", guidelines on how to prepare it, examples produced by teachers and a set of rubrics and criteria that contribute to guide planning in the context of teaching in the health professions.
\end{abstract}

Keywords: Educational Planning; Higher Education; Health; Faculty; Teacher Training.

\footnotetext{
Universidade de São Paulo, Faculdade de Medicina de Ribeirão Preto, Centro de Apoio Educacional e Psicológico, Ribeirão Preto, SP, Brasil Universidade de São Paulo, Faculdade de Medicina de Ribeirão Preto, Centro de Apoio Educacional e Psicológico, Ribeirão Preto, SP, Brasil Universidade de São Paulo. Faculdade de Medicina de Ribeirão Preto, Ribeirão Preto, SP, Brasil. Professor Associado do Departamento de Puericultura e Pediatria
} 


\section{MENSAGENS PRINCIPAIS:}

- $\quad$ Mais do que um instrumento a ser preenchido, o plano de ensino e aprendizagem representa um momento importante de escolha, reflexão e de tomada de decisão para a formação dos sujeitos.

- Investir tempo nessa ação de planejar trará benefícios consistentes para o processo educativo, afinal, é "pensando criticamente a prática de hoje ou de ontem que se pode melhorar a próxima prática".

\section{INTRODUÇÃO}

Entre os inúmeros substantivos que representam sucessos e insucessos no nosso viver em sociedade, encontra-se o planejamento. Geralmente, passados muitos anos ou às vezes poucos dias, se algo não funcionou como previsto, é comum ouvir a máxima: "faltou planejamento".

O significado da palavra se aplica a muitos aspectos e tem como definição no dicionário online Houaiss": "ação de preparar um trabalho, ou um objetivo, de forma sistemática; planificação"; "ação ou efeito de planejar, de elaborar um plano", ou, ainda, "determinação das etapas, procedimentos ou meios que devem ser usados no desenvolvimento de um trabalho (...)".

Vale dizer que, do ponto de vista educacional, o planejamento é um ato político-pedagógico, uma vez que revela uma intencionalidade, tornando explícito aquilo que o corpo docente pretende alcançar em relação à aprendizagem dos estudantes.

As várias construções sociais, ideológicas, culturais que atravessam uma determinada sociedade e época estarão presentes nos processos de ensinar e aprender, e, como diz Zabala² "por trás de qualquer proposta metodológica se esconde uma concepção do valor que se atribui ao ensino". Entende-se que, ao se descrever quais elementos são essenciais para que o ensino se efetive em aprendizagem, é necessário considerar que a escolha destes dependerá das concepções e contexto de dada comunidade acadêmica.
Considerando o campo da Educação Superior no Brasil, há vários documentos que precisam ser levados em conta por gestores de cursos e docentes quando se discute planejamento educacional. Eles partem de um nível macro (Diretrizes e Projetos Pedagógicos) e vão se afunilando para o contexto da sala de aula, do ambiente educativo como o Plano de Ensino e Aprendizagem (PEA) ou Plano de Aulas ${ }^{3}$, como também é conhecido.

Neste relato de experiência, o leitor encontrará como Pontos de Interesse:

- Uma definição sobre PEA, bem como as partes que o compõem, no contexto da Faculdade de Medicina de Ribeirão Preto, Universidade de São Paulo (FMRP-USP);

- A recente história que levou à discussão e implementação do PEA reformulado para os cursos de graduação da FMRP;

- O oferecimento de condições formativas para que os docentes pudessem se apropriar do instrumento PEA, assim como perceber as potencialidades de reflexão que o material traz para a prática docente, e;

- A apresentação de uma rubrica com elementos norteadores para a elaboração do PEA, os principais pontos a serem levados em conta ("virtudes") e aquilo que se deve evitar fazer ("pecados").

\section{Plano de Ensino e Aprendizagem: oportu- nidades para reflexão}

O PEA de determinada disciplina, estágio ou módulo deve estar em consonância com o Projeto Pedagógico (PP) do curso em que ele está inserido. Por sua vez, esse PP deverá estar ancorado nas orientações gerais presentes nas Diretrizes Nacionais Curriculares (DCN). Como o relato de experiência que se segue refere-se às profissões da saúde, podemos dizer que as $\mathrm{DCNs}^{4}$ trazem elementos norteadores para a formulação dos PPs dos cursos, tais como o perfil do egresso, competências e habilidades, conteúdos curriculares, estágios e atividades complementares, avaliação dos estudantes, organização e acompanhamento do curso voltados para a demandas do SUS. 
Investir na elaboração de bons PEAs se torna possível quando partimos deste ponto estruturante, quando consideramos as realidades concretas de cada conjuntura e reconhecemos que o ato de planejar exige de nós um conhecimento sobre a educação, seus valores e significados, um conhecimento sobre o educando e sua inserção na história, o seu processo de desenvolvimento e aprendizagem, bem como um conhecimento seguro dos conteúdos científicos com os quais se deseja trabalhar ${ }^{5}$.

O planejamento envolve reflexão, organização, sistematização, previsão, decisão e outros aspectos na pretensão de assegurar a eficácia de uma ação $0^{6}$. Todo esse processo, com seus episódios mobilizadores de discussões e etapas que dirigiram à reformulação do PEA da FMRP, faz parte deste relato.

\section{Relato de Experiência}

As mudanças possuem histórias e certamente são fruto de uma produção coletiva complexa. Se atualmente temos um PEA mais robusto em forma e conteúdo, ele é proveniente de uma construção feita a muitas mãos, tendo emergido de um contexto profícuo para isso.

Em 2017, focando-se em sua missão, a Comissão de Graduação (CG) da FMRP vinha num processo de intensa valorização do ensino, fomentando a realização reuniões e eventos com a comunidade acadêmica para discutir e implementar melhorias nos processos de ensino.

Nessa mesma época, as Comissões Organizadoras (COCs) de cada um dos sete cursos da FMRP, por sua vez, investiram em reuniões ordinárias e extraordinárias (batizadas como COCs temáticas), nas quais um colegiado ampliado (com docentes e estudantes dos vários anos) analisava os desafios e as possibilidades próprias de seus contextos a partir de relatórios sobre as avaliações das disciplinas organizadas pelo Centro de Avaliação em Ensino de Graduação (CAEG), instância assessora da CG.

Paralelamente, o Centro de Desenvolvimento Docente para o Ensino (CDDE) promovia o Módulo Básico para as profissões da saúde, um curso voltado à capacitação de docentes e preceptores vinculados à FMRP e/ou ao Hospital das Clínicas da FMRP-USP, com vistas à melhoria do processo de ensino/aprendizagem para a graduação.

O Centro de Apoio Educacional e Psicológico (CAEP), por meio da equipe de pedagogos, compunha comissões, prestava assessorias e dava suporte a estudantes e docentes e incentivava a discussão sobre a elaboração de novos PEAs.

Esse efervescente cenário contribuiu para que ocorressem acontecimentos importantes, como o Fórum de Ensino da Graduação, com o tema: "Planejamento do Processo de Ensino e Aprendizagem" (ocorrido em junho de 2018) e - V Simpósio de Graduação (ocorrido em agosto de 2018), cuja temática abordou a "Flexibilização dos conhecimentos para uma formação generalista nas profissões da saúde".

Neste último, houve a distribuição de estudantes, professores e gestores em cinco grupos distintos, que se debruçaram sobre a discussão das temáticas indicadas na Tabela 1, abaixo:

\section{Tabela 1. Temáticas discutidas no $\mathbf{V}$ Simpósio de Graduação da FMRP-USP (agosto/2018).}

Temáticas discutidas

$\mathrm{N}$ de

participantes

A) Diversidade e peculiaridades dos 7

41 cursos da FMRP

B) Planejamento Educacional I: Roteiros de aulas

C) Planejamento Educacional II: Estratégias de Ensino e avaliação

D) Flexibilização Curricular I: Revisão e adequação de conteúdos

E) Flexibilização Curricular II: Gestão do tempo, carga horária e autonomia do estudante

\section{TOTAL}

201

Ao final do $V$ Simpósio, organizou-se um plano de ação detalhado, de modo que as discussões feitas não se encerrassem ali, mas, sim, tivessem continuidade em outras situações específicas. Dentre as metas estabelecidas, a revisão e atualização dos roteiros de aulas, úteis a professores e estudantes, tinha destaque. Para tanto, 
algumas ações como a criação e aprovação de um novo modelo de PEA (ocorrida na 863a Reunião Ordinária da CG-FMRP-USP, de 27/8/2019), o oferecimento de oportunidades para aprender como elaborar os instrumentos propostos em situações organizadas, a divulgação para a comunidade, entre outras, foram prioridades.

\section{Oportunidades para discussão dos PEAs e Desenvolvimento Docente}

No intuito de auxiliar na reflexão e elaboração dos PEAs das disciplinas dos cursos da FMRP, o CAEP realizou os "Encontros Pedagógicos" (espaços para troca de ideias, experiências e informações entre docentes e pedagogos do Centro de Apoio).

Os Encontros foram divulgados no site da Faculdade e na lista de e-mails dos professores. Foram oferecidos em momentos distintos, com duas horas de duração, sendo conduzidos pelos educadores que atenderam grupos de professores (quartetos ou quintetos), duplas ou até mesmo quem vinha sozinho. Neles, os responsáveis por ministrar disciplinas, coordenadores de disciplinas e de curso, gestores de semestre, interagiram com os profissionais da educação para debater, esclarecer dúvidas, contar sobre suas atuações e se apropriar mais do material a ser produzido. As reflexões contaram com um material de apoio com perguntas disparadoras sobre planejamento, charges, bibliografias, sugestões sobre o uso de verbos que melhor expressassem os objetivos de aprendizagem e as operações de pensamento, as quais desejavam mobilizar os estudantes com suas atividades, etc. Foram momentos de aprendizado e descontração.

Mas, ao nos depararmos em 2020 com a Pandemia da Covid-19, outras reflexões foram necessárias. Na modalidade à distância, ocorreram Encontros Pedagógicos preocupados com as demandas relativas a essas mudanças, mas, sem dúvidas, um dos canais que favoreceu muito a discussão sobre a inclusão da cultura digital nos PEAs foi a parceria entre educadores e professores em uma das sessões do Curso de Capacitação e-disciplinas na Educação Remota emergencial (ERE) e na Educação a Distância (EaD), promovido pela equipe do CDDE da FMRP-USP, que contou com mais de 80 participantes em suas duas edições.

\section{A mudança do PEA: novo modelo, no- vas descobertas, novo aprendizado}

\footnotetext{
(Clique aqui para conhecer um template preenchido como exemplo.)

O novo PEA adotado pela FMRP foi aprovado na 863a Reunião Ordinária da Comissão de Graduação da FMRP-USP, realizada em 27/08/2019, e buscou substituir o antigo instrumento chamado de Roteiro de Aulas, uma vez que este trazia informações muito genéricas, com referência a apenas alguns itens, tais como: horário de aula, turma, tipo de atividade (teórica ou prática), o tema e o(s) docente(s) responsável(is). Apesar dessa organização ter tido sua importância durante um tempo, havia a necessidade de avançar para que o novo instrumento trouxesse maior detalhamento e que pudesse auxiliar professores e estudantes, baseado nos seguintes objetivos:
} 


\section{Plano de Ensino e Aprendizagem (PEA)}

\begin{tabular}{|l|l|}
\hline ELEMENTOS DE IDENTIFICAÇÃO DA DISCIPLINA \\
\hline Curso \\
\hline Código e nome da disciplina & \\
\hline Período de oferecimento & \\
\hline Coordenadores & \\
\hline Docentes & \\
\hline
\end{tabular}

\begin{tabular}{|l|l|}
\hline CARGA HORÁRIA \\
\hline Teórica & \\
\hline Estudo dirigido & \\
\hline Hora Trabalho & \\
\hline$\ldots$ & \\
\hline Total & \\
\hline
\end{tabular}

\section{CONTEXTO:} palavras).

Quais as contribuições de sua disciplina para a formação desse profissional? (Máx: 500

Para melhor compreender o contexto do curso para qual leciona, você pode buscar o Projeto Político Pedagógico na página CENTRAL da FMRP (www.fmrp.usp.br) na área dos cursos. Ou então, agendar um encontro com as Coordenações dos Cursos (COCs) para construírem conjuntamente aquilo que é relevante de sua disciplina para o perfil do profissional a ser formado.

\section{MATRIZ DE COMPETÊNCIAS}

Esta matriz pode ser pensada para a disciplina como um todo ou pode ser utilizada no preenchimento do template que se destina a cada aula.

\begin{tabular}{|c|c|c|}
\hline O que será aprendido? & Como será aprendido? & Como será avaliado? \\
\hline $\begin{array}{c}\text { Organizar em forma de objetivos } \\
\text { de aprendizagem (com os } \\
\text { domínios cognitivos, } \\
\text { procedimentos/habilidades, } \\
\text { atitudinais) }\end{array}$ & $\begin{array}{c}\text { Estratégias de ensino e } \\
\text { aprendizagem }\end{array}$ & Avaliação: \\
- cognitivos \\
\end{tabular}

\section{TEMPLATE:}

No modelo a seguir você encontrará espaços referentes aos elementos que devem compor o seu Planejamento de Ensino e Aprendizagem diário. No quesito avaliação, você pode preencher na horizontal adequando aos dias em que irá ocorrer a avaliação ou na vertical, caso pretenda aplicá-la em todas as aulas. 
Esclarecer ao estudante os resultados esperados em termos de competências a serem adquiridas, nos domínios cognitivo, psicomotor e atitudinal, por meio de cada disciplina/estágio que estiver cursando;

- Descrever e detalhar a contribuição da disciplina para a futura prática profissional, bem como contextualizar a aplicação desse conhecimento em cada área de atuação;

- Descrever clara e sucintamente os objetivos, estratégias de ensino e aprendizagem, e formas de avaliação, de modo que o estudante seja corresponsável pela sua formação profissional.

Gerar planejamentos que demonstram a relação teoria-prática e caminham na direção de um currículo mais integrado entre as suas várias etapas, exigirá um esforço coletivo de todos os protagonistas do contexto acadêmico, desde sua concepção, execução até a avaliação.

Para tanto, O PEA foi dividido em duas partes: o Planejamento Geral da Disciplina e o Plano das aulas.

\section{$1^{\text {a }}$ Parte - Planejamento Geral da Disciplina}

Nessa parte, espera-se que a disciplina, módulo ou estágio, mais uma vez, considere o perfil de egresso que o curso pretende formar. A partir desse entendimento e ponto de partida, se inicia o desenvolvimento de suas etapas, descritas a seguir:

- Elementos de identificação

Nessa parte inicial se apresenta: o nome do Curso; Código; Nome da disciplina; Período de oferecimento; Carga horária; Coordenação e docentes responsáveis pelo desenvolvimento das atividades. Espera-se que a disciplina esteja sendo oferecida no momento mais adequado para a formação dos estudantes.
- Contexto: significando o aprendizado

Essa etapa do PEA é crucial e contribui para motivar o estudante a aprender ainda mais. $O$ contexto da disciplina tem como essência revelar quais são as suas contribuições para a formação do estudante naquele momento em que ele está vivendo e experienciando a graduação. Nesse item, é relevante apontar a existência de integração e interlocução da própria disciplina com outras que a precederam, com as que coexistem no semestre e com aquelas que virão adiante. Também é um momento importante para aportar se a disciplina possui características de introdução, fundamentos, aprofundamento, retomada ou consolidação de determinados assuntos.

- Estabelecendo os propósitos educacionais de maneira global: a matriz

A primeira página do PEA da FMRP possui um Quadro Matriz (Figura 2) para que o docente apresente sua disciplina de maneira geral. Descrevê-la de forma "panorâmica" e visual auxilia a percebê-la em sua totalidade, como um verdadeiro mapa daquilo que se pretende ensinar ( $O$ QUE), como se pretende ensinar (COMO/QUAIS serão as estratégias) e como se pretende avaliar (COMO/QUAIS serão as formas/métodos de avaliação).

O foco da aprendizagem precisa seguir na direção do desenvolvimento de competências, que podem ser entendidas como a mobilização articulada dos domínios cognitivos (conhecimentos, fatos), procedimentais (habilidades) e afetivos ou atitudinais (valores, atitudes, crenças) que se espera que o estudante adquira para atuar de forma condizente com o perfil de egresso proposto no PP e nas DCNs. [Clicando aqui, o leitor terá acesso a uma animação que explica de forma simplificada como a competência pode ser entendida]. 
Esta matriz pode ser pensada para a disciplina como um todo ou pode ser utilizada no preenchimento do template que se destina a cada aula.

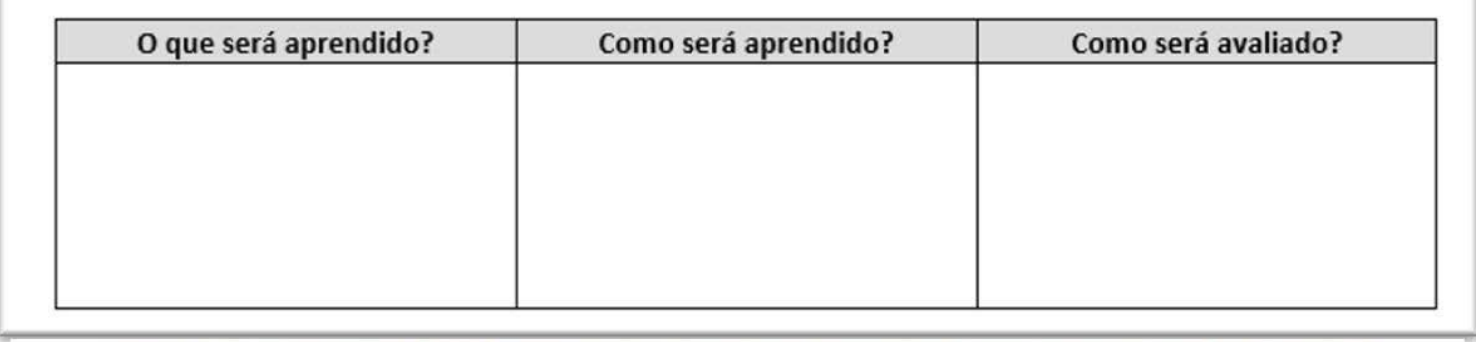

Figura 2: Quadro matriz a ser preenchido de forma mais ampla no Planejamento Geral da Disciplina

Além disso, para dar mais clareza quanto à intenção daquilo que se quer ensinar no processo, na descrição dos objetivos, o verbo deve estar no infinitivo, pois refere-se a uma ação pretendida. Abaixo, uma síntese que poderá ajudar nessa etapa:

Os objetivos ligados ao domínio cognitivo envolvem as operações do pensamento necessárias à aquisição de conhecimentos, como, por exemplo: descrever, classificar, comparar, resumir, resenhar, interpretar, criticar, obter e organizar dados e hipóteses, entre outros.

Os objetivos associados ao domínio procedimental direcionam as ações práticas e habilidades a serem desenvolvidas, como, por exemplo: aplicar, planejar, executar, desenvolver, projetar, atuar, realizar procedimentos, etc.<smiles>C1=[Si]2CCCC(C2)[Si]1</smiles>
Os objetivos ligados ao domínio atitudinal agrupam valores, atitudes, assim como normas e princípios éticos. Contemplam as relações de convivência, posturas e sentimentos e podem ser descritos como, por exemplo: compartilhar, respeitar, comunicar, decidir, valorar, adotar postura respeitosa em relação à, etc.

Em suma, na matriz do PEA é esperado que estejam destacados objetivos que delimitam $O$ QUE será ensinado na disciplina, COMO e quais serão as estratégias por meio das quais eles serão trabalhados e COMO se dará a avaliação.
CONTEÚDOS EDUCACIONAIS: ESTABELECENDO OS SABERES E AS PRÁTICAS DA FORMAÇÃO PROFISSIONAL

Outro tópico que constitui o PEA da FMRP é a reflexão que o docente pode fazer respondendo à seguinte indagação: Quais os saberes e práticas que cabem à minha disciplina/módulo/estágio para o contexto da formação profissional do(s) curso(s) em que estou atuando?

Mais uma vez, o PP do curso em que irá atuar poderá dar as pistas necessárias sobre as competências gerais e específicas daquela profissão, o que ajudará que ele priorize conteúdos essenciais, considerando sua expertise, os conhecimentos historicamente acumulados e as trocas entre os pares para tomar as melhores decisões, uma vez que sua disciplina é a parte de um todo. Atualmente, também é importante lembrar que o docente pode e deve basear sua escolha em evidências científicas.

Nesse momento, diante do PEA, o docente pode criar uma imagem geral dos conteúdos que necessitará para, na segunda parte, distribuí-los entre cada aula. Trabalhar esses saberes e práticas, demanda a valorização do professor em relação às suas escolhas, mas, também, o respeito pela carga horária estabelecida, a consideração sobre o tempo de estudo do aprendiz e o fato de que ele cursa, simultaneamente, outras disciplinas. ${ }^{* 1}$

\footnotetext{
*1 A matriz curricular da instituição na qual a experiência se deu é disciplinar, todavia as mesmas sugestões podem ser aplicadas a outros modelos curriculares. Os docentes envolvidos na elaboração dos PEAs foram estimulados a pensar em uma perspectiva interdisciplinar e interprofissional.
} 


\section{$2^{a}$ Parte - Plano de aula e seu detalha- mento}

A segunda parte do PEA contém o Plano das Aulas. Ele refletirá, temporalmente, a ação docente por meio da explicitação dos objetivos, os conteúdos, as metodologias empregadas, os procedimentos avaliativos e, se recomenda fortemente, os momentos reservados para fornecer as devolutivas (feedback) para o estudante e/ou sua turma sobre o andamento do aprendizado. Mesmo que este documento seja comumente entre- gue antes do início das aulas para ser aprovado pelas COCs, no contexto da FMRP, é preciso que, no decorrer de seu desenvolvimento, haja espaço para eventuais flexibilizações e ajustes daquilo que foi proposto inicialmente.

No modelo proposto para o PEA há espaços destinados para que o professor coloque a data, o horário, o local da atividade, a turma, o conteúdo/tema principal a ser desenvolvido naquele dia e, como dito, os objetivos, as estratégias, os períodos de avaliação e o(s) docente(s) responsável(eis), como se vê na Figura 3 abaixo:

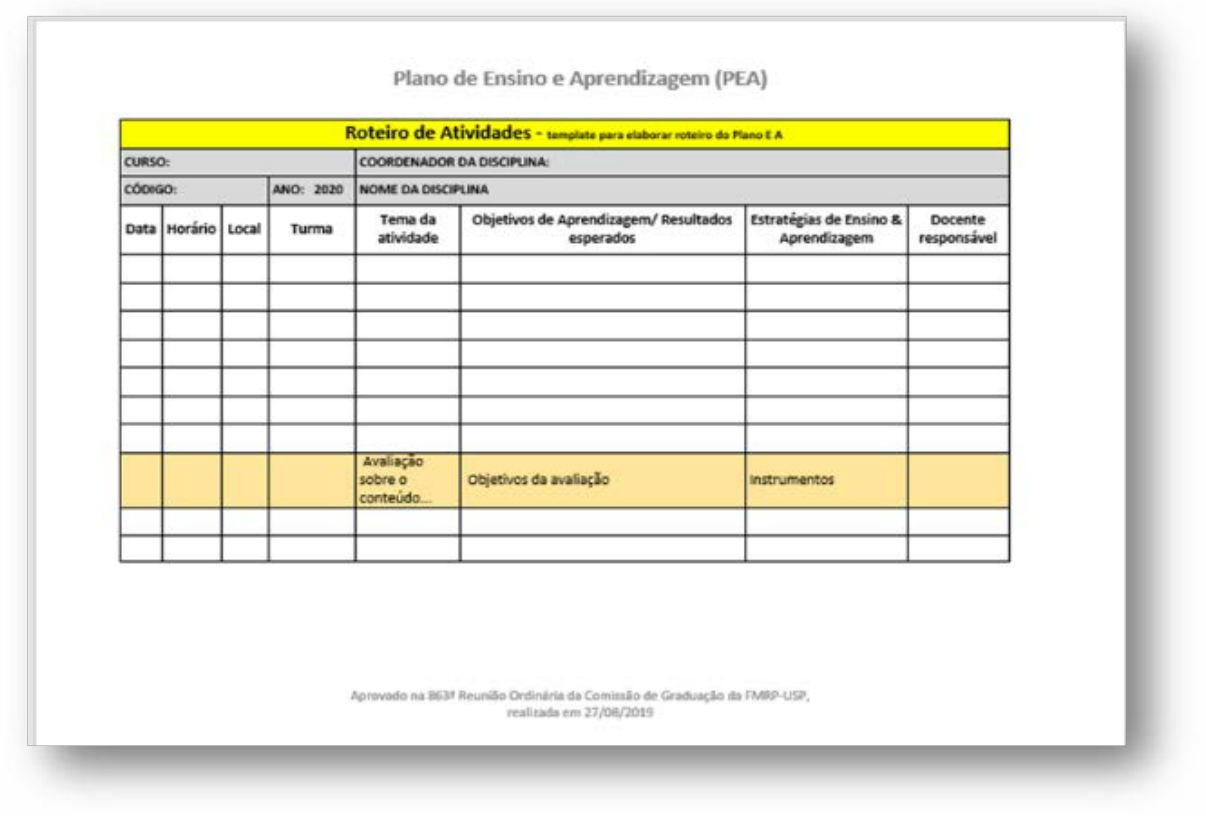

Figura 3: Parte 2 do PEA: detalhamento do Roteiro de Atividades da disciplina

\section{REFORÇANDO IDEIAS E OS PASSOS PARA ELABORAÇÃO DO PEA}

- Na coluna sobre o Tema da atividade/Conteúdos, ressalta-se: Que saberes permitem atingir esses propósitos?

A partir dos saberes e dos conteúdos que foram estabelecidos na primeira parte do PEA, nesse espaço, o docente tem a complexa tarefa de decidir quais serão aqueles essenciais para cada aula. Para isso é necessário que o professor dedique tempo a essa tarefa a fim de examinar diligentemente como o conteúdo a ser ministrado naquele dia dialoga com os objetivos de aprendizagem. Todo esse esforço faz sentido quando retomamos as críticas que o educador Dewey $^{7}$, na década de 40 do século $X X$, faz às escolas por não estarem "desenvolvendo a capacidade de discriminação crítica, a capacidade de raciocinar de seus estudantes" assim como, "a capacidade de pensar se perde na miscelânea de informações acumuladas e mal digeridas"

$\mathrm{Na}$ coluna central do PEA estão os Objetivos de aprendizagem, que podem levar 0 docente a se indagar: Quais são os propósitos educacionais que pretendo atingir por meio dessa disciplina? 
Nas palavras de Libâneo 8 , "os objetivos educacionais são uma exigência indispensável para o trabalho docente, requerendo um posicionamento ativo do professor em sua explicitação, seja no planejamento escolar, seja no desenvolvimento das aulas". Distribuir e detalhar em cada aula o que se espera do ponto de vista da aprendizagem do estudante permite colocá-lo em uma posição central no processo educativo.

Como se espera que na primeira parte do PEA o docente já tenha explicitado os objetivos gerais na perspectiva dos domínios cognitivos, procedimentais e atitudinais, nesse momento, ele terá a liberdade de aplicá-los sem necessariamente classificá-los em domínios. O mais importante é ter o entendimento que, se conseguir traduzir nos objetivos gerais tudo o que se espera do futuro profissional (desde o saber técnico até as posturas éticas), ao estabelecer os específicos, todos os domínios estarão entrelaçados.

- Na coluna Estratégias de Ensino e Aprendizagem se definem: Quais as metodologias educacionais que permitem atingir os propósitos/objetivos de aprendizagem definidos? Como fazer isso?

A aprendizagem envolve uma série de condições que se aglutinam e distintos perfis de estudantes que estão como pano de fundo quando o docente tem que decidir "como" irá trabalhar para alcançar os objetivos de aprendizagem.

Para Anastasiou', por meio das estratégias aplicam-se ou exploram-se os meios, modos e formas de evidenciar o pensamento, respeitando as condições favoráveis para executar ou fazer algo. Os procedimentos devem superar a memorização e identificação e avançar no sentido de mobilizar o estudante para operações de pensa- mento mais complexas. É essencial que a escolha da estratégia se volte para metodologias consideradas ativas, por colocar o estudante numa condição ativa para lidar com os diferentes conhecimentos e realidades.

Assim que os objetivos de aprendizagem e os conteúdos estiverem bem estabelecidos, concomitantemente, se define a estratégia educacional mais adequada, lembrando que, por exemplo, um conteúdo tido como cognitivo, exigirá uma estratégia diferente de um procedimental. Quanto mais diversificadas as estratégias puderem ser, melhor será o atendimento às diferentes necessidades de aprendizagem e aos diferentes estilos e formas de aprender dos estudantes.

Aplicar novas estratégias não é uma tarefa fácil e talvez, para alguns, a mudança da educação presencial para uma lógica remota possa ter representado um desafio ainda maior. Diante de toda mudança, Zabalza ${ }^{10}$ acredita que sua operacionalização deva ocorrer através de pequenos passos e com a consciência que sempre haverá uma margem de incertezas, receios e até contradições. O autor acrescenta, ainda, que é necessário "estar sensível" aos que serão mais afetados pelas mudanças.

Para além das estratégias de ensino e aprendizagem presenciais, despontam também aquelas que alguns autore ${ }^{11}$ classificam como ferramentas/estratégias tecnológicas em razão de suas funções e do contexto no qual serão utilizadas para dar melhor direcionamento ao ensino. A seguir, a título de ilustração, segue um quadro que apresenta uma classificação sobre as ferramentas que podem ser exploradas na educação remota, já que foi preciso uma adaptação brusca a novas formas de ensinar diante do contexto pandêmico: 
- Ferramentas de comunicação assíncrona (forum de discussão, e-mail, grupos de whatsapp)

- Ferramentas de comunicação síncrona (plataformas ou aplicativos para chat em áudio ou video)

- Ferramentas de instrução assincronas (podcasts,mapas conceituais ou mentais,videos (curtos), gamificaçăo, problematizaçăo, pesquisa em bases bibliograficas)

- Ferramentas de instruçăo sincronas (videos (curtos), , exames de imagens, softwares 3D, discussăo de casos, problematizaçăo, teste, simulaçăo virtual

- Ferramentas colaborativas: Plataformas para trabalhos em grupos, enquetes, projetos, seminários, gincanas,games, portifólio eletrônico colaborativo, wikis

- Ferramentas de pesquisa de opinião(enquete, questionários, múltipla escolha);

- Ferramentas de avaliação: gamificação, testes de multipla escolha, casos/situações problema, simulação virtual, feedback automático ou interativo, portifolio eletronico

- Ferramentas de administraçăo(perfil do aluno, criaçăo de grupos, banco de dados, diários de classe, controle de frequência, geração de relatórios, gráficos e estatisticas de participaçăo).

Quadro 1: Caracterização das funções das ferramentas para educação remota, segundo MANNING, S.; JOHNSON, K.

Vale ressaltar que, independentemente da estratégia a ser adotada, além do estudo sobre elas, é sempre bom trocar experiências com outros parceiros mais experientes sobre o que cada um pretende fazer.

- O template do PEA ainda lembra que é preciso se pensar na Avaliação, o que leva a considerar: Como é possível determinar se esses propósitos estão realmente sendo atingidos?

A reflexão docente sobre sua prática e sobre a aprendizagem do estudante deve ocorrer antes, durante e depois da execução de suas ações didáticas. Ao preparar o PEA, é importante considerar o alinhamento (ou espelhamento) entre aquilo que se pretende avaliar com os objetivos de aprendizagem que haviam sido elaborados nas aulas e outros contextos de aprendizagem, considerando os critérios já pactuados e comunicados aos estudantes.

O processo de avaliação deve ser coerente com as aprendizagens que eram esperadas e que, de fato, foram desenvolvidas ao longo das semanas, meses, semestre, ano. De maneira geral, a avaliação do estudante é tida como um processo de coleta, análise e interpretação de informações sobre o desempenho nos domínios cognitivo, psicomotor e afetivo, bem como nas competências próprias a esses domínios, com vistas à tomada de decisões, tanto sobre o progresso do estudante, quanto para fomentar a aprendizagem e/ou para o aperfeiçoamento do processo educacional.

$\mathrm{Na}$ educação presencial, a avaliação chama a atenção por ser um ponto alto no desenvolvimento e, predominantemente, na culminância de uma disciplina. Mas, como fazê-la? Que método(s) utilizar? Qual será aquele(s) que melhor se aplica àquilo que o docente quer considerar?

Se no ensino presencial essas definições são desafiadoras, na realização da educação remota, elas se tornam maiores, uma vez que não cabe apenas a pura transposição de um formato para outro.

Embora haja muitas ferramentas capazes de ajudar o docente a realizar uma boa avaliação à distância, algo que precisa estar sempre em pauta desse processo é o caráter formativo e a necessidade de destinar momentos sistemáticos para fornecer feedback para os estudantes sobre como têm sido os seus desempenhos. O feedba$c k$, componente essencial da avaliação, "regula o processo de ensino-aprendizagem, fornecendo, continuamente, informações para que o estudante perceba o quão distante, ou próximo, ele está dos objetivos almejados"12.

Shute $^{13}$ define feedback formativo como momentos contínuos, nos quais "toda informação 
comunicada ao estudante com o objetivo de alterar o seu pensamento ou comportamento, tendo como resultado a melhoria da aprendizagem".

Por essa razão, se faz necessário a previsão de espaços e tempos para que a disciplina mantenha uma regularidade com essa prática, bem como a capacitação institucional do docente para realizá-la bem. Durante a escolha das tarefas a serem feitas, a colaboração e o diálogo entre as disciplinas do semestre são essenciais, pois se houver uma sobrecarga de tarefas solicitadas ao mesmo tempo, algum aprendizado poderá ser prejudicado.

\section{UMA RUBRICA PARA A ELABORAÇÃO DO PEA}

Na tentativa de colaborar com o fazer docente, se investiu na criação de uma rubrica, ou seja, um instrumento guia, na forma de quadro, com elementos importantes a serem considerados para a elaboração de um PEA. Elaborada pela equipe de educadores da FMRP, a rubrica foi utilizada no curso de Capacitação em Educação Remota para docentes, organizado pelo CDDE da FMRP-USP, em meados de 2020, como se vê abaixo:

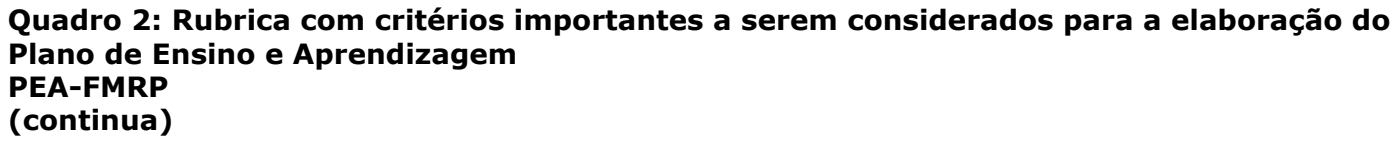

\begin{tabular}{|c|c|c|c|c|c|}
\hline Parte 1 & Descritores & $\begin{array}{l}\text { Não } \\
\text { contempla }\end{array}$ & $\begin{array}{l}\text { Contempla } \\
\text { parcialmente }\end{array}$ & Contempla & Amplia \\
\hline $\begin{array}{l}\text { Elementos de } \\
\text { apresentação } \\
\text { da disciplina }\end{array}$ & $\begin{array}{l}\text { Realiza identificação da disciplina } \\
\text { (Curso; Código; Nome da disciplina; } \\
\text { Período de oferecimento; Carga horária; } \\
\text { Coordenação e docentes responsáveis } \\
\text { pelo desenvolvimento da disciplina). }\end{array}$ & & & & \\
\hline \multirow{4}{*}{ Contexto } & $\begin{array}{l}\text { Apresenta as contribuições da disciplina/ } \\
\text { estágio para a formação do estudante } \\
\text { naquele momento do curso. }\end{array}$ & & & & \\
\hline & $\begin{array}{l}\text { Faz referência a documentos institucio- } \\
\text { nais como PP (Projeto Pedagógico). }\end{array}$ & & & & \\
\hline & $\begin{array}{l}\text { Estabelece relações com o perfil do } \\
\text { egresso que se pretende formar. }\end{array}$ & & & & \\
\hline & $\begin{array}{l}\text { Indica se a disciplina é de introdução ou } \\
\text { aprofundamento. }\end{array}$ & & & & \\
\hline \multirow{4}{*}{$\begin{array}{l}\text { Objetivos } \\
\text { Educacionais } \\
\text { Gerais como } \\
\text { Matriz de } \\
\text { competências }\end{array}$} & $\begin{array}{l}\text { Os objetivos se pautam nas compe- } \\
\text { tências do perfil do profissional a ser } \\
\text { formado. }\end{array}$ & & & & \\
\hline & $\begin{array}{l}\text { Os objetivos de aprendizagem contem- } \\
\text { plam os domínios cognitivos; procedi- } \\
\text { mentais e atitudinais a serem aprendidos } \\
\text { na disciplina como um todo (matriz de } \\
\text { competências). }\end{array}$ & & & & \\
\hline & $\begin{array}{l}\text { Descreve o modo como serão desenvol- } \\
\text { vidos os domínios cognitivos, procedi- } \\
\text { mentais e atitudinais. }\end{array}$ & & & & \\
\hline & $\begin{array}{l}\text { Descreve como serão avaliados os } \\
\text { domínios cognitivos, procedimentais e } \\
\text { atitudinais. }\end{array}$ & & & & \\
\hline
\end{tabular}




\begin{tabular}{|c|c|c|c|c|c|}
\hline Parte 2 & Descritores & $\begin{array}{l}\text { Não con- } \\
\text { templa }\end{array}$ & $\begin{array}{l}\text { Contempla } \\
\text { parcialmente }\end{array}$ & Contempla & Amplia \\
\hline $\begin{array}{l}\text { 2.1. Quadro/ } \\
\text { Roteiro das } \\
\text { aulas }\end{array}$ & $\begin{array}{l}\text { As datas, horários, turmas } \\
\text { e locais (ainda que virtuais) } \\
\text { foram descritos. }\end{array}$ & & & & \\
\hline $\begin{array}{l}\text { 2.2. Tema/ } \\
\text { conteúdo }\end{array}$ & $\begin{array}{l}\text { Descreve com clareza os } \\
\text { tópicos e subtópicos que serão } \\
\text { abordados (temas). }\end{array}$ & & & & \\
\hline \multirow{3}{*}{$\begin{array}{l}2.3 \text {. } \\
\text { Objetivos de } \\
\text { aprendiza- } \\
\text { gem/ } \\
\text { Resultados } \\
\text { esperados }\end{array}$} & $\begin{array}{l}\text { Apresenta os objetivos indican- } \\
\text { do as ações que se pretende } \\
\text { realizar (verbos no infinitivo). }\end{array}$ & & & & \\
\hline & $\begin{array}{l}\text { Trabalha saberes e práticas } \\
\text { com perspectiva interdiscipli- } \\
\text { nar. }\end{array}$ & & & & \\
\hline & $\begin{array}{l}\text { Trabalha saberes e práticas } \\
\text { com perspectiva interprofis- } \\
\text { sional. }\end{array}$ & & & & \\
\hline \multirow{3}{*}{$\begin{array}{l}\text { 2.4. Estra- } \\
\text { tégias de } \\
\text { Ensino para } \\
\text { o formato } \\
\text { remoto }\end{array}$} & $\begin{array}{l}\text { Apresenta diversidade de es- } \\
\text { tratégias para o ensino } \\
\text { (videoaula, fórum, enquetes, } \\
\text { discussão de casos clínicos, } \\
\text { estudos dirigidos, seminários, } \\
\text { reuniões MConf, Google meet, } \\
\text { etc.). }\end{array}$ & & & & \\
\hline & $\begin{array}{l}\text { As estratégias mobilizam o } \\
\text { estudante para participar mais } \\
\text { ativamente da aula. } \\
\text { Declara que irá disponibilizar } \\
\text { as aulas gravadas previamente } \\
\text { e/ou as ministradas online. }\end{array}$ & & & & \\
\hline & Inclui plantão de dúvidas. & & & & \\
\hline \multirow{4}{*}{$\begin{array}{l}2.5 . \\
\text { Avaliação }\end{array}$} & $\begin{array}{l}\text { Utiliza diferentes momentos } \\
\text { para avaliar o estudante (Ava- } \\
\text { liação Formativa). }\end{array}$ & & & & \\
\hline & $\begin{array}{l}\text { Realiza uma única avaliação ao } \\
\text { final da disciplina. }\end{array}$ & & & & \\
\hline & $\begin{array}{l}\text { Detalha o(s) método(s) de } \\
\text { avaliação. }\end{array}$ & & & & \\
\hline & $\begin{array}{l}\text { Explicita os critérios de apro- } \\
\text { vação. }\end{array}$ & & & & \\
\hline \multirow[b]{2}{*}{ Bibliografia } & $\begin{array}{l}\text { Há bibliografia básica dispo- } \\
\text { nível. }\end{array}$ & & & & \\
\hline & $\begin{array}{l}\text { Há bibliografia complementar } \\
\text { disponível. }\end{array}$ & & & & \\
\hline $\begin{array}{l}\text { Aparência } \\
\text { geral do PEA }\end{array}$ & $\begin{array}{l}\text { O visual possui aparência que } \\
\text { deixa o documento claro. }\end{array}$ & & & & \\
\hline
\end{tabular}


Além da rubrica, a experiência vivenciada permitiu elencar alguns pontos que decidimos compartilhar como "virtudes" ou "pecados", no que se refere à elaboração de planos de ensino e aprendizagem

\section{Quadro 3: Sete "Virtudes" e "Pecados" sobre o PEA}

7 "Virtudes"

1. Pensar na disciplina como um todo e sua posição dentro do curso;

2. Lembrar que professor e estudante, ambos são protagonistas do processo de formação;

3. Convidar parceiros experientes e estudantes a partiIhar as decisões relativas ao PEA e a sua efetivação;

4. Valorizar as histórias e contextos de sua própria realidade;

5. Conectar a avaliação da aprendizagem aos objetivos educacionais;

6. Dialogar com os pares e gestores para obter ações educacionais colaborativas, diante das limitações humanas e estruturais existentes;

7. Ser flexível, pois a educação (e a vida) estão em constante movimento.

\section{7 "Pecados"}

(ou o que não fazer)

1. Achar que sua disciplina ou curso é o mais importante naquela etapa de formação do estudante, desconectada do curso como um todo;

2. Listar objetivos educacionais vagos, muito ambiciosos, muito específicos, ou inatingíveis naquele estágio de formação;

3. Exigir do estudante dedicação em tempo superior ao destinado à sua disciplina;

4. Utilizar apenas uma estratégia de ensino e aprendizagem, ignorando a diversidade de condições e estilos de aprendizagem de cada estudante;

5. Enfatizar o que é muito específico ou exceção, desviando o foco do que é mais geral e, de fato, relevante e mais comum;

6. Criar um ambiente de tensão e medo, levando os estudantes a se sentirem inseguros quanto a sua capacidade e ameaçados em sua progressão no curso;

7. Avaliar o estudante sem considerar os objetivos educacionais propostos, fazendo perguntas "de rodapé" e não abordando os assuntos e conceitos principais que de fato o estudante precisaria saber.

\section{CONSIDERAÇÕES FINAIS}

No momento em que a comunidade da FMRP estava se adaptando paulatinamente ao novo formato e à nova concepção do PEA, a imprevisibilidade da vida bateu à porta da instituição pedindo um lugar para o ensino remoto dentro desses planejamentos educacionais.

Foi importante nesse momento contar com Comissões Organizadoras, Centros de Apoio e de Desenvolvimento Docente, docentes e estudantes alinhados à missão de valorizar cada vez mais o ensino de graduação e com o compromisso de multiplicar os saberes em relação ao PEA. Todos já tinham compreendido a importância do trabalho colaborativo, oportunizando espaços que permitiram ao corpo acadêmico (docentes, estudantes, educadores) construir coletivamente os elementos básicos de um planejamento educacional para atender de forma mais integrada às necessidades peculiares do perfil de cada profissional em formação. Nesse processo, tornou-se fundamental ampliar as discussões sobre o PEA, considerando que o paradigma da aprendizagem havia mudado e que pensar na educação híbrida também envolveria refletir em muitos outros fatores, como adotar medidas que pudessem garantir a equidade das condições de acesso e formas de cuidar melhor das complexas necessidades educacionais de discentes e docentes que emergiram nesse tempo.

À luz das teorias mencionadas e dos resultados da experiência, conclui-se que a construção de um bom PEA favorece a ação mais ativa, reflexiva e crítica do professor sobre a sua prática e, consequentemente, o instiga a conhecer com mais profundidade as necessidades educacionais contemporâneas para a formação do profissional nas áreas da saúde. Contudo, tornou-se evidente que os graus de dificuldade ainda se apresentam neste caminho e continuam necessitando de acompanhamento e apoio. A adaptação da comunidade ao novo PEA, no que tange a necessidade de escrever com clareza sobre a importância de sua disciplina para a formação de determinada profissão e o que espera que seu aluno aprenda, 
bem como a necessidade de diversificar estratégias de ensino e aprendizagem e métodos de avaliação, são desafios permanentes a serem enfrentados de forma coletiva, apostando na competência da comunidade acadêmica, na valorização das conquistas processuais deste trabalho e na reafirmação da capacitação docente como um pilar institucional imprescindível.

\section{REFERÊNCIAS BIBLIOGRÁFICAS:}

1. Houaiss, A. Dicionário on-line Houaiss da língua portuguesa. [acesso em: 8 fev. 2021]. Disponível em: https://www.dicio.com.br/houaiss/.

2. Zabala, A. A prática educativa: como ensinar. Ernani $F$. da F. Rosa, tradutor. Porto Alegre: Artmed; 1998. 224p.

3. Reis FJC dos, Panúncio-Pinto MP, Vieira MNCM. Planejamento educacional. Medicina (Ribeirão Preto) [Internet]. 3 de novembro de 2014 [acesso em: 12 de fevereiro de 2021];47(3):280-3. Disponível em: https:// www. revistas.usp.br/rmrp/article/view/86616

4. Ministério da Educação (BR). Conselho Nacional de Educação, Câmara de Educação Superior. Resolução CNE/ CES no 4, de 07 de Novembro de 2001: Institui as diretrizes curriculares nacionais do curso de graduação em medicina. Diário Oficial da União, Brasília, 9 Nov. 2001. Seção. 1, p. 38.

5. Luckesi, CC. Planejamento, Execução e Avaliação no Ensino - A Busca de um desejo. Rev da FAEEBA [Internet]. 1993. [acesso em 12 fev. 2021]; 2: 137-52. Disponível em:_https://www.revistas.uneb.br/index.php/faeeba/ article/view/657/494.
6. Leal, RB. Planejamento de ensino: peculiaridades significativas. Rev Iberoamericana de Educação [Internet]. 2005. [acesso em: 15 fev. 2021]; 37(3): 1-7. Disponível em: https://rieoei.org/historico/deloslectores/1106Barros.pdf.

7. Dewey, J. Experiência e educação. Tradução Anísio Teixeira. Coleção Atualidades Pedagógicas. Volume 131: 90. $3^{a}$ Edição. São Paulo: Companhia Editora Nacional, 1979

8. Libâneo, JC. Didática. São Paulo: Cortez; 2013.

9. Anastasiou, LGC, Alves, LP. Processos de ensinagem na universidade: pressupostos para as estratégias de trabalho em aula. Joinville: UNIVILLE; 2007.

10. Zabalza M Ángel. Los planes de estudio en la universidad. Algunas reflexiones para el cambio. REFU [Internet]. 2015 [citado 28 de janeiro de 2021];(1). Disponível em: https://revistascientificas.us.es/index.php/ fuentes/article/view/2289

11. Manning, S, Johnson, KE. The technology toolbelt for teaching. São Francisco/EUA: Jossey-Bass, 2011. In: Rodrigues $\mathrm{HZ}$, et al. Taxonomia e Matriz de Decisão das Tecnologias Digitais na educação: proposta de apoio à incorporação da tecnologia em sala de aula. Tec. Soc. e Con. [Internet]. 190 de novembro de 2015 [citado 2 de fevereiro de 2021];2(1):85-104. Disponível em: https://econtents.bc.unicamp.br/inpec/index.php/tsc/ article/view/14451

12. Borges, MC, Miranda, CH, Santana, RC, Bollela, VR. Avaliação formativa e feedback como ferramenta de aprendizado na formação de profissionais da saúde. Medicina, Ribeirão Preto, 47(3): 324-31, 2014.

13. Shute, VJ. Focus on Formative Feedback. Review of Educational Research, v. 78, n.1, p.153-89, 2008.

14. Freire, P. Pedagogia da Autonomia. 33.ed. São Paulo: Paz e Terra; 1996. 
Corresponding Author:

Cristiane Martins Peres

cris@fmrp.usp.br

Editor:

Prof. Dr. Marcelo Riberto

Recebido: $30 / 04 / 2021$

Aprovado: 13/07/2021

(c) (i) Este é um artigo publicado em acesso aberto (Open Access) sob a licença Creative

sem restrições, desde que permite uso, distribuiçao e reprodução em qua 